\title{
Bending Moments to Business Models: Integrating an Entrepreneurship Case Study as Part of Core Mechanical Engineering Curriculum
}

\section{Dr. Mark Schar, Stanford University}

MARK SCHAR works in the Center for Design Research - Designing Education Lab at Stanford University. He is also a member of the Symbiotic Project of Affective Neuroscience Lab at Stanford University and a Lecturer in the School of Engineering. Dr. Schar's area of research is "pivot thinking" which is the intersection of design thinking and the neuroscience of choice where he has several research projects underway. He has a 30 year career in industry as a Vice President with The Procter \& Gamble Company and Senior Vice President and Chief Marketing Officer with Intuit in Silicon Valley. Dr. Schar has a BSS from Northwestern University, an MBA from the Kellogg School of Management and his PhD is from Stanford University.

\section{Dr. Sheri Sheppard, Stanford University}

Dr. Sheppard is a professor at Stanford University, teaching courses in engineering design and solid mechanics. Her research is in the areas of structural integrity and engineering learning. Her graduate work was at the Univ. of Michigan, and prior to being at Stanford she worked in the automotive industry.

\section{Ms. Samantha Brunhaver, Stanford University}

Samantha Brunhaver is a fifth year graduate student at Stanford University. She is currently working on her PhD in Mechanical Engineering with a focus in engineering education. Samantha completed a BS in Mechanical Engineering from Northeastern University in 2008 and a MS in Mechanical Engineering with a focus in Design for Manufacturing from Stanford in 2010.

\section{Mr. Mark Cuson}

Mark Cuson is a sophomore studying Mechanical Engineering at Stanford University. After several education related jobs in the past, he decided to spend the summer after his freshman year working on engineering education, specifically Stanford's Introduction to Solid Mechanics, E14. In addition to the Longboard Lab \& Case Study, Mark worked on a series of online vector math tutorials to ease the transition into E14.

Michelle Marie Grau, Stanford University 


\title{
Bending Moments to Business Models: Integrating an Entrepreneurship Case Study as Part of Core Mechanical Engineering Curriculum
}

\begin{abstract}
This is a pilot study of an instructional technique that teaches important solid mechanics concepts within the context of an entrepreneurship case study and lab. Students were tested preand-post the case study/lab experiences to determine changes in engineering and entrepreneurial content knowledge, entrepreneurial self-efficacy and career intent. Results show that students can increase their knowledge of targeted entrepreneurship concepts without diminishment of learning core engineering concepts. While the case study experience did not significantly change entrepreneurial career intentions it did grow students' perceived entrepreneurial self-efficacy (as measured by confidence in business skills), which can be a precursor to changing career intent. The case study experience also appealed to a broad spectrum of students with career interests ranging from working for a start-up to working for an established global business. The implications of entrepreneurial case study instruction are discussed.
\end{abstract}

\section{Introduction}

The career pathway for engineering students overwhelmingly leads to industry. A recent study by the National Science Foundation of newly graduated engineering bachelor and master's degree recipients shows that 75 percent of graduates are employed by "private industry or business." It is apparent from reports like The Engineer of $2020^{2}$ that an engineer's education would benefit from instruction in a broader range of career-based skills, particularly in business. An important career-based skill is entrepreneurship that at its core seeks to deliver new and unique goods and services to customers. The Engineer of 2020 refers to this process as "customerization" and states that in the future, increasingly:

"Engineers will be asked to accelerate and expand customerization as businesses compete to build and maintain a strong customer base, wherever those customers may be." (p37)

However, traditional engineering curriculum leaves little time for extra coursework. A recent study of 110 U.S.-based engineering programs showed that less that 20 percent "routinely practice" any type of business or entrepreneurship activity ${ }^{3}$. In general, engineering faculty has not embraced the teaching of entrepreneurship; only 16.5 percent routinely engage engineering students in entrepreneurship ${ }^{3}$. This stands in contrast with student attitudes; in one recent study 82 percent of engineering students agreed with the statement "entrepreneurship education can broaden my career prospects and choices." $"$

In this study we explore the benefits and challenges of integrating entrepreneurship into core engineering curriculum. This is accomplished by combining a business school-style case study featuring a realistic entrepreneurial scenario with a typical engineering lab. The case study "Madison Longboard" chronicles two engineering student graduates as they start a company that makes skateboards specialized for marathon competition. The case study introduces several 
entrepreneurial concepts, such as business models, mission statements, and SWOT analysis, in the context of product development that requires calculation of static forces that lead to design and sourcing decisions. Two engineering labs on forces, moments, and normal bending stresses help resolve the business problem presented in the case study.

\section{Case Study Method Instruction}

Engineers working in business require the ability to solve relevant engineering problems "in uncertain and even currently unknowable environments." The pedagogical goal of the case study method is to create this environment in the minds of students while they learn new concepts and solve important problems. The case study method is widely used in business schools to explore "the 'wicked' problems that potential managers will face in an uncertain world" and encourage the "development of critical thinking and sense making abilities."7 Over time, the case study method has become a popular teaching tool because its been shown to help the student connect theory with a practical application that increases the relevance of the potential solution ${ }^{8}$. Case-based instructional methods have long been used in engineering education, almost exclusively in the context of ethics where "there is widespread agreement that the best way to teach professional ethics is by using cases.",

Less common is the use of the case study method to integrate business learning, specifically entrepreneurship concepts, with core engineering curriculum. Weaver and Rayess, ${ }^{10}$ on behalf of the KEEN Network, have developed a series of short case studies across a variety of entrepreneurial situations that are incorporated into various engineering courses. Garcia et al. ${ }^{11}$ tested an entrepreneurial case study within a civil engineering course that covered topics such as market segmentation and a rudimentary competitive analysis, subjects not typically covered in a core engineering curriculum. In both studies, post intervention research reported high levels of student engagement and satisfaction with the case study technique, as well as enthusiasm for entrepreneurship. However, there was no indication of either the extent or quality of the entrepreneurial learning or the impact on the core engineering learning.

In an attempt to prepare engineers for a business career many educational institutions have adopted a pedagogical approach that can generally be described as "design thinking." While the concept of design thinking can mean many things, the definition by Tim Brown, President and CEO of IDEO, provides a relevant framework. Brown describes design thinking as:

“... a discipline that uses the designer's sensibility and methods to match people's needs with what is technologically feasible and what a viable business strategy can convert into customer value and market opportunity." 12

The pedagogical goal of design thinking is innovation. It is achieved by finding the intersection of what is feasible (typically the domain of engineering), with what is viable or profitable (typically the domain of business schools) with what is desirable. Design innovation is the intersection of these activities ${ }^{13}$, as shown in Figure 1. 


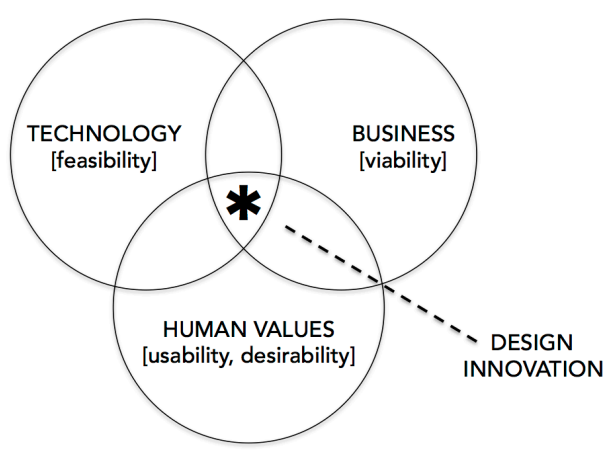

Figure 1 - A design thinking framework

Within engineering education, design innovation is usually achieved through a capstone experience, and many good examples of this exist within the engineering education community. However, capstone experiences can be resources-intensive, taking a substantial amount of time (often a semester or academic year ${ }^{14}$ ) and significant funding to deliver on design thinking pedagogical goals. An advantage of engineering case study instruction is the ability to engage students in design thinking (technology, business and human values) on a topic-by-topic basis, with relatively small investment of time and resources.

\section{Research Questions}

A primary concern relating the introduction of entrepreneurial content within core engineering coursework is the displacement of engineering teaching time, resulting in a diminishment of core engineering conceptual learning. This is why within most engineering programs entrepreneurial instruction and experiences are often relegated to extracurricular activity ${ }^{3}$. On the other hand, business schools have effectively used the case study method to not only teach core business skills but to instill critical thinking skills that help the student navigate in a world that is "complex and ambiguous with no right answers and no single explanation of events." $\mathrm{We}$ hypothesize that a well-designed case study can deliver both a thorough understanding of the core engineering concepts and a significant increase in understanding of basic entrepreneurial concepts. Our first research question asks:

\section{(Q1) Does the introduction of entrepreneurial concepts into a core engineering curriculum diminish the learning of core engineering concepts?}

As engineering students prepare for a post graduation career, they consider several factors. Social Cognitive Career Theory (SCCT) posits that career interests develop overtime as a function of self-efficacy and the expected outcome related to a career choice ${ }^{15,16}$. While we are not proposing this research as a test of the social-cognitive model, the elements of SCCT can be helpful in structuring our questions. For example, the case study method can help students build entrepreneurial self-efficacy by showing how their engineering knowledge (and new business knowledge) can help solve key entrepreneurial problems. In addition, the case study story can highlight potential positive outcomes of a successful entrepreneurial experience. Measures of academic satisfaction have been used as a proxy for a student's outcome expectations within the SCCT model ${ }^{17}$ and we propose using student satisfaction with the case study and lab experience for this analysis. 
Our second and third research questions are:

(Q2) Do students with a career interest in entrepreneurship report greater satisfaction in a case study experience than students with a lesser interest in entrepreneurship?

(Q3) Does a case study experience improve a student's entrepreneurial self-efficacy (as indicated by confidence in business skills)?

Building self-efficacy involves a process that Bandura refers to as "human agency" defined as "to intentionally make things happen by one's actions." 18 This is a cognitive process that leads to a specific behavior or action. While Bandura suggests that true changes to self-efficacy require "repeated exposures to modeled preferences," 19 we are curious if a one-time exposure to an entrepreneurial experience via a case study can have an effect on long-term entrepreneurial intentions among students in a core engineering class. Therefore, our fourth and final research question is:

(Q4) Will students' career interest in entrepreneurship change pre-to-post a single entrepreneurial case study experience?

\section{Methods}

This pilot research was conducted to determine if it was possible to integrate an entrepreneurial case study into core engineering curriculum and, to a lesser extent, to measure the efficacy of the pedagogy. As a result, this research contains no randomized controls and therefore lacks the ability to make causal inferences about the effect or impact of educational experiences. The case study and labs were integrated into a 10-week, 20-session introductory engineering solid mechanics course at a western private university in fall and winter quarters of the 2012-2013 academic year. A week-by-week overview of the class is shown in Table 1.

\begin{tabular}{clll} 
Week & Topics & Lab & Homework \\
\hline 1 & $\begin{array}{l}\text { Forces: Vocabulary, Representations and Manipulation - } \\
\text { Math Basics }\end{array}$ & Tower Design & Forces \\
\hline 2 & Moments: Representation and Equivalent Load & Longboard -Trucks & Moments \\
\hline 3 & $\begin{array}{l}\text { Equilibrium: Summing Forces and Moments } \\
\text { Entrepreneurship Case Study }\end{array}$ & Device Operation & Fntrepreneurship \\
\hline 4 & Free Body Diagrams: The Key Image & Hyatt Ethics Case & Trusses \\
\hline 5 & $\begin{array}{l}\text { Equilibrium: Analysis and Trusses } \\
\text { Safety Factors - Ethics }\end{array}$ & Design Exercise & Bridge Report \\
\hline 6 & Bridges: Design and Construction & Bicycle Analysis & \\
\hline 7 & Analysis of Machines & Longboard - Deck & Frames, Machines, Beams \\
\hline 8 & $\begin{array}{l}\text { Analysis of Beams: Loads and Stresses } \\
\text { Entrepreneurship Case Study }\end{array}$ & & $\begin{array}{l}\text { Friction and Statically } \\
\text { Indeterminate }\end{array}$ \\
\hline 9 & $\begin{array}{l}\text { Statically Indeterminate Problems } \\
\text { Role of Friction in Equilibrium }\end{array}$ & Final Project Poster Session \\
\hline 10 & Analysis of Distributed Loads & & \\
\hline
\end{tabular}

Table 1 - Solid Mechanics course overview by-week showing learning topics and placement of the two (highlighted) entrepreneurial case study/labs 
The class includes 7 in-class labs, as well as a final, student directed project. Each class session lasted about two-hours and generally the first weekly class session was dedicated to a lecture on the relevant solid mechanics topics, while the second weekly class included a hands-on lab experience.

- Participant Demographics: The participant base included 174 students over the two quarters. Participation in the surveys was either voluntary or for small "homework reward" points. Participants in the first quarter completed four surveys, which allowed for pre-to-post comparisons. This was judged overly burdensome, so the second quarter participants completed two surveys, all post lab experience. Between the two quarters, data were collected on 160 students (92\% participation) and the resulting participant sample is 38.1 percent female, 20.3 mean years of age. As participation was voluntary, sample sizes vary by question. Most of the respondents were planning to declare a mechanical engineering major (but at this stage of their education many have not officially declared a major) and other students expressed interest in civil engineering, physics and mathematics.

- Case Study Method Curriculum: The two-part case study was developed to involve two lab experiences - analysis of beams (referred to as Longboard - Trucks) and elasticity of materials (referred to as Longboard - Deck). The case study incorporated 12 engineering concepts drawn from the undergraduate engineering course text $\mathrm{t}^{20}$ and 10 entrepreneurial concepts selected from a popular graduate-level textbook on entrepreneurship ${ }^{21}$. Each part of the case study involved 4-6 pages of text, 1-2 exhibits and required about 30 minutes outside of class to read. The course mechanical engineering professors presented the case study and briefly discussed the entrepreneurial concepts. In total, about 30 minutes of class time (out of 20 hours for the quarter) were dedicated to classroom discussion of the entrepreneurial concepts. The concept topics included in the case study are shown in Table 2 and a complete list of the topics covered in this class is shown in Attachment A.

\begin{tabular}{|l|lll|}
\hline \multicolumn{2}{|c|}{ Engineering Concepts } & \multicolumn{2}{c|}{ Entrepreneurial Concepts } \\
\hline \multicolumn{1}{|c|}{ Longboard - Trucks } & \multicolumn{1}{c|}{ Longboard - Deck } & Longboard - Trucks & Longboard - Deck \\
\hline Normal force & Modulus of elasticity & Business model & Vision statement \\
Normal stress & Deflection & Value proposition & Mission statement \\
Moments & Neutral Axis & Revenue model & SWOT analysis \\
Moment center & Cantilever beam & Cost model & Business risk \\
Planar systems & Bending stress & Profit model & Business uncertainty \\
Safety Factor & Design for safety & &
\end{tabular}

Table 2 - Key learning concepts included in the two-part case study and labs

The narrative of the case study involved a realistic entrepreneurial scenario about two recently graduated mechanical engineering students from the University of Wisconsin who decide to start a company that makes longboards (a type of skateboard) specialized for marathon-distance competition. The characters (one male, one female) offer different points of view on the approach to the business and design of the product. The first part of the case deals with the forces on the longboard trucks (wheel assembly) and then using these data to choose a potential supplier, of which there are two (of four) viable options. The second part 
of the case involves selecting a deck material (from three choices) and then designing the longboard deck (length, width and depth) to meet both safety and aesthetic criteria.

- Lab Elements/Worksheet: Each part of the case study was accompanied by a four-page worksheet that was mostly completed in class during the lab experience. The fourth page of each worksheet covered the entrepreneurial concepts and was completed as class homework. The lab experiences were designed to use practical and inexpensive materials an entrepreneurial engineer might use to help make decisions. The Longboard - Trucks lab (beam analysis) used two joined meter sticks, rolling weights and a jeweler's scale to estimate rider-induced loads at different points on the longboard. The Longboard - Deck lab (deflection) used strips of material (maple, plywood and polycarbonate/acrylic), L-brackets for support, a card to mark deflection distance and a luggage scale to exert force. The set-up for each lab is shown in Figure 2.

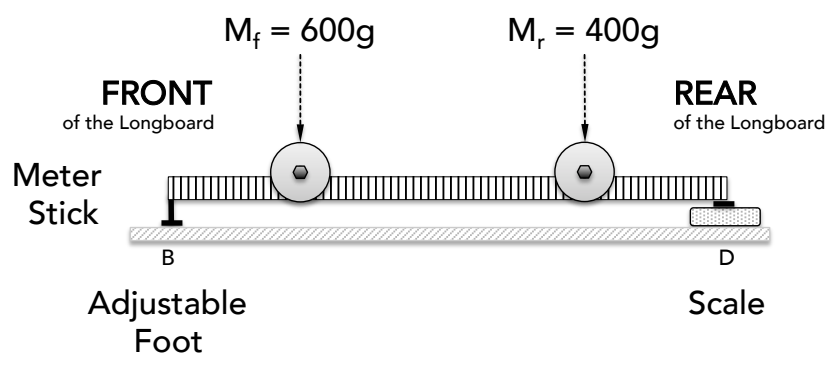

Longboard - Trucks: Beam Analysis

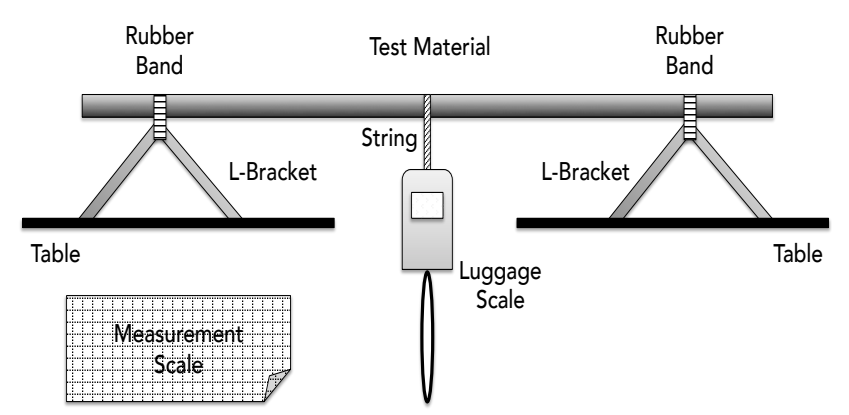

Longboard - Deck: Deflection

Figure 2 - Longboard Lab materials and set-up

- Content Questions: The student respondents completed four on-line surveys in fall quarter, which were administered before and after the Longboard - Trucks and Longboard - Deck experiences. In the winter quarter, two on-line surveys were completed, after each of the two lab experiences. Each survey contained 10 content questions ( 5 engineering and 5 entrepreneurship), which were unique to each lab, resulting in 20 total pre-post content measures ( 10 engineering and 10 entrepreneurial). The content questions had between 4 and 5 multiple choice answers, which were presented in random order. Demographic, career intent, and self-efficacy questions were asked before the first lab and after the second lab; lab experience questions were asked following each lab experience (see below). Stanford University Institutional Review Board (IRB) approved the survey and research protocol.

- Measure of Career Intent: Student respondents were asked once before the Longboard Trucks lab experience and a second time after the Longboard - Deck lab experience about their career intention using the question, "Looking into your future, over the 5 years from your graduation how likely are you to do any of the following?" The choices included selfemployed, small business/start-up, medium or large size US-based business, multi-national global business, government and non-profit. Responses were collected using a 5-point Likert 
scale of likelihood ranging from Very Unlikely (1) to Very Likely (5) with (3) as neutral. This question was adapted from a longstanding alumni survey instrument ${ }^{22}$.

- Measure of Self-Efficacy - Skills: Student respondents were asked pre-and-post each of the two lab experiences about their confidence to perform in a series of business-related skills. This item was drawn from previous studies on engineering persistence ${ }^{23,24}$. The question was "How confident are you in your ability to do each of the following at this time?" The eight choices included recognizing a good idea, financing a new business, marketing approach, negotiating prices with a supplier, leading a team of people, and promoting accomplishments. Responses were collected using a 5-point Likert scale of confidence ranging from Not Confident (1) to Extremely Confident (5) with 3 as neutral. The self-efficacy of businessrelated skills scale showed high reliability (Cronbach's alpha $=0.84$ pre and 0.82 post).

- Measures of Case Study and Lab Satisfaction: Student satisfaction on the overall case study and in-class lab experience was measured with a question drawn from Garcia et al. ${ }^{11}$ This question asked about satisfaction with the case study experience and included 8 items ranging from "the case study helped me synthesize ideas and information from the course" to "the case study allowed me to view an issue from multiple perspectives, " including two items that were reverse scored to help eliminate selection bias. Responses were collected using a 5point Likert scale of agreement ranging from Strongly Disagree (1) to Strongly Agree (5) with (3) as neutral. The items had high reliability (Cronbach's alpha $=.80$ ), so the items were averaged to form a single the Case Study/Lab Satisfaction (CSLS) Score.

- Student conceptual maps: As a course-concluding exercise, students were asked to draw a map of the concepts included within this entire course experience. After brief instruction on conceptual maps, students were given a list of the topics covered in class and asked to draw a conceptual map linking these ideas together that reflects their understanding of the course. We were interested in how students would link the entrepreneurial concepts in the context of the core engineering curriculum concepts. A representative sample $(n=38)$ of these maps were analyzed using the techniques described by Turns et al. ${ }^{25}$ with pre-defined concepts, where the core concept (center point) is recorded as a starting point and then all first order hierarchical associations are recorded. Key linkages between first order concepts are defined using a "holistic approach" described by Besterfield-Sacre ${ }^{26}$.

- Statistical Analyses: This analysis focuses primarily on the student respondents who answered all pre-and-post questions for each scale. Normality was assessed using the Shapiro-Wilk test, and the data were found to be normally distributed. Single-sample pairedcomparison t-tests were performed. Correlations were done as Pearson Product Moment Correlations with two-tailed significance. The level of statistical significance for all analysis is $\mathrm{p}$-value $<0.05$.

\section{Results}

(Q1) Does the introduction of entrepreneurial concepts into a core engineering curriculum diminish the learning of core engineering concepts? 
Overall, there is evidence that students' knowledge of both engineering and entrepreneurial concepts increased through the case study and lab experience. Of the 20 questions asked (10 engineering and 10 entrepreneurial) in the pre-surveys, students correctly answered an average of 10.4 questions, and this increased to 13.3 mean correct answers in the post-survey, a statistically significant increase of +2.9 mean correct answers, as shown in Table 3 . It is encouraging to note that there were similar increases in both engineering content questions $(+26 \%)$ and entrepreneurship content questions $(+29 \%)$, indicating a balanced impact on learning

\section{Questions}

Engineering (out of 10)

Entrepreneurial (out of 10)

Total (out of 20)

\# bold is significant

\begin{tabular}{|c|c|c|c|c|c|}
\hline \multicolumn{3}{|c|}{ Correct Answers } & \multirow[b]{2}{*}{ Increase } & \multirow[b]{2}{*}{ Difference } & \\
\hline $\mathbf{n}$ & Pre & Post & & & $\mathbf{p}<$ \\
\hline 75 & 5.3 & 6.7 & $+26 \%$ & +1.4 & .000 \\
\hline 75 & 5.1 & 6.6 & $+29 \%$ & +1.5 & .00 \\
\hline$\overline{75}$ & $1 \overline{0.4}$ & $1 \overline{3.3}$ & $\overline{+28 \%}$ & $\overline{+2.9}$ & .00 \\
\hline
\end{tabular}

Table 3 - Mean Correct Answers to Content Questions Pre-to-Post-Lab Experiences for both the engineering and entrepreneurial concepts (about 50\% correct compared to a 20-25\% level associated with random guessing) indicated that students come to this experience with a significant knowledge base. Also, the relatively low level of correct answers post the case study and lab experience (about 67\%) and its consistency across subjects suggests more learning may be possible through refinement of the teaching process.

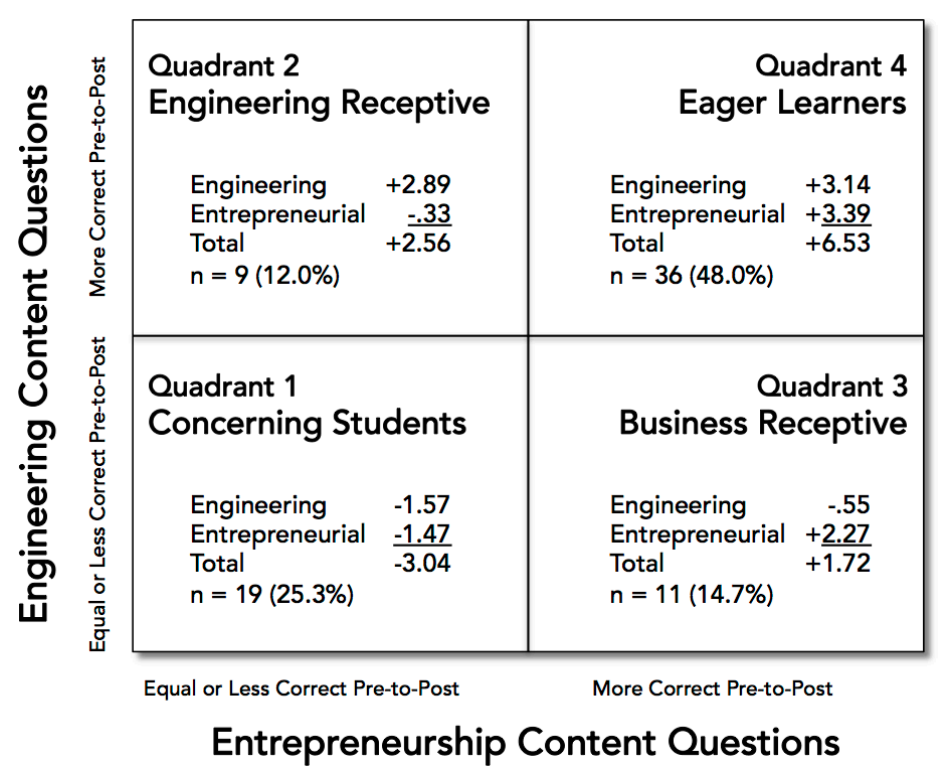

Figure 3 - Quadrant analysis by Pre-to-Post Changes in Mean Correct Answers to Content Questions

It was also clear that increased learning was not consistent among all students, as shown in Figure 3. Some students showed increased learning for the engineering concepts and not entrepreneurial concepts, other students showed just the opposite. Some students showed no 
growth in learning in either category and some students showed significant increases in learning in both engineering and entrepreneurial concepts.

It is encouraging that the largest grouping of students, we call "Eager Learners" (Quadrant 4 $48.0 \%$ of students), showed significant increase in pre-post learning of both engineering and entrepreneurship concepts. Recall, the mean number of correct answers for the combined engineering and entrepreneurial questions was +2.9 pre-to-post, while the "Eager Learner" group had +6.53 mean correct answers: +3.14 engineering answers and +3.39 entrepreneurial answers pre-to-post. This supports the underlying hypothesis of this research that students can learn engineering and entrepreneurial concepts concurrently.

Equally interesting is that two additional groups emerged, "Engineering Receptive" (Quadrant 2 - $12.0 \%$ of students) and "Business Receptive" (14.7\% of students) who exhibit diametrically opposed learning experiences. The "Engineering Receptive" showed a statistically significant increase in mean correct answers to the engineering concepts $(+2.89)$ and about the same level of mean correct answers to the entrepreneurial concepts (-.33). The "Business Receptive" students showed an opposite significant increase in mean correct answers to entrepreneurial concepts $(+2.27)$ and about the same level of mean correct answers to the engineering concepts $(-.55)$.

Finally, a noteworthy portion of the students, we call "Concerning Students" (Quadrant 1 $25.3 \%$ of students) showed a significant decrease in mean correct answers to both engineering content questions (-1.57) and entrepreneurial content questions (-1.47). It is not clear why this these decreases occurred. There is no significant pattern of age, gender or career intent associated with Quadrant 1 students and, as will be shown, these students reacted positively to the case study and lab experience.

Based on the overall mean correct answer increase for both engineering and entrepreneurial concept questions, we find evidence to support our hypothesis that students can increase their knowledge of targeted entrepreneurship concepts without diminishing the learning of core engineering concepts.

\section{(Q2) Do students with a career interest in entrepreneurship report greater satisfaction in a case study experience than students with a lesser interest in entrepreneurship?}

Students' career intent was measured with a 6-item question that included a range of career choices, as shown in Table 4. There were no significant differences in career intent pre-to-post for the fall quarter students, so results were averaged across the two surveys and combined with results from the winter quarter students.

Results show that students in this study have a significant interest in an entrepreneurial career, specifically working for a start-up business. While self-employment had a mean likelihood rating of 2.95 (versus 3.0 neutral), working for a start-up had a mean likelihood rating of 3.61, significantly above neutral. A significant portion of students rated "self-employed" (32\%) and "working for a start-up" (65\%) as either "likely" or "very likely" career options post graduation. 
After graduation, how likely are you to:

... be Self-Employed

... work for Start-Up

... work for Medium/Large US Business

... work for Multi-National Global Business

... work For Government

... work For Non-Profit

\section{Mean Rating*}

\subsection{5}

3.61

3.66

3.46

2.81

2.86

$\mathbf{p}<* *$
.571
.000
.000
.000
.025
.084

4-5 Rating \#

47
97
108
83
46
44

\begin{tabular}{c} 
\% Sample \\
\hline $32 \%$ \\
$65 \%$ \\
$73 \%$ \\
$56 \%$ \\
$31 \%$ \\
$30 \%$
\end{tabular}

$\mathrm{n}=149 * 3.0$ is the neutral score $* *$ statistical difference from the neutral score, bold is significant \# number of students who answered "Likely" (4) or "Very Likely" (5) to this career option

Table 4 - Career Intent as measured by Likelihood of Post-Graduation Employment.

Working for a larger, existing business was also interesting to students as medium/large US business or multi-national global business had mean ratings of 3.66 and 3.46, both significantly above neutral, and a large portion of students (73\% and $56 \%$, respectively) indicated this was a likely or very likely career option post graduation. Finally, working for government or a nonprofit organization had overall lower than neutral ratings, but still a significant number of students (31\% and $30 \%$, respectively) listed this as a likely or very likely career choice. It should be noted that it is possible for one student to fall in several groups, reflecting both the varied and uncertain career interest of students at this stage of their educational experience.

On a separate note, mean career intent ratings were highest for working in a "medium-to-large US-based business" or a "multi-national global business." In fact, these ratings equal or exceed the career intent ratings for working for a start-up or founding a business. This supports an approach that focusing solely on start-up entrepreneurship may be limiting with students relative to their career intent, and that emphasizing both entrepreneurship in a start-up business and a existing business (sometimes called "intrapreneurship"27) may be an effective way to shape learning experiences that introduce business skills and concepts into an engineering curriculum.

Student satisfaction with the case study and lab experiences was measured with an 8-item question. As previously indicated in Methods, these items had high reliability (Cronbach's alpha $=.80$ ), so the items were averaged to form a single the Case Study/Lab Satisfaction (CSLS) Score. This score was calculated by student career intent and by student learning quadrants, as shown in Table 5.

\begin{tabular}{|c|c|c|c|c|c|c|c|}
\hline Career Intent & $\underline{\mathbf{n}}$ & CSLS Score* & $\mathbf{p}<\#$ & Learning Quadrant & $\underline{\mathbf{n}}$ & CSLS Score* & $\mathbf{p}<\#$ \\
\hline Self-Employed & $4 \overline{5}$ & 3.04 & .659 & Concerning Students (Q1) & $1 \overline{9}$ & 3.31 & .029 \\
\hline Start-Up & 93 & 3.16 & .003 & Engineering Receptive (Q2) & 9 & 2.93 & .643 \\
\hline M/L US Business & 102 & 3.16 & .002 & Business Receptive (Q3) & 11 & 3.31 & .010 \\
\hline Global Business & 79 & 3.21 & .000 & Eager Learners (Q4) & 36 & 3.13 & .128 \\
\hline Government & 43 & 3.23 & .005 & & & & \\
\hline Non-Profit & 43 & 3.21 & .007 & Total CSLS & 158 & 3.13 & .003 \\
\hline
\end{tabular}

Table 5 - Case Study/Lab Satisfaction (CSLS) Score by Career Intent and by Learning Quadrant. 
Overall, the Case Study/Lab Satisfaction (CSLS) Score was 3.13, statistically significant above neutral suggesting that students approved of the case study and lab experience. Students who expressed an interest in a start-up career had a statistically positive rating for the case study and lab experience, which is encouraging given the subject of the case study was a start-up company. It is also encouraging to note that students who expressed an interest in working for a medium/large US business, a global multi-national business, government work and non-profit work also had positive ratings for the case study and lab experience. (Recall, an individual student can fall into several groups) Students who expressed a likelihood of self-employment were the only career intent groups to rate the case study and lab experience as neutral.

The learning quadrant groups also rated the case study experience differently. Not surprisingly, students in the "Business Receptive" quadrant had a 3.31 rating to the case study experience, the highest score of any group and statistically significantly higher than both a neutral score and the overall average score. Conversely, the "Engineering Receptive" quadrant had a score of 2.93, the lowest of any group, and while not statistically different than neutral, it is significantly lower than the ratings of the "Business Receptive" quadrant. It is also important to note that the "Concerning Students" quadrant had a score of 3.31, significantly above average, which suggest something other than satisfaction with the case study experience suppressed their pre-to-post correct content question scores.

Based on this, we find evidence to support our hypothesis that a stronger interest in entrepreneurship, in this case "working for a start-up," will be associated with a greater satisfaction with an entrepreneurial case study experience. We are also encouraged that the case study experience had appeal to students interested in other career paths including established business, government and non-profit careers.

\section{(Q3) Does a case study experience improve a student's entrepreneurial self-efficacy (as indicated by confidence in business skills)?}

Students' entrepreneurial self-efficacy was measured with an 8-item question that included a range of common business skills, as shown in Table 6. A principal component analysis with Varimax rotation (and Kaiser normalization) of the post-lab experience ratings was conducted on this sample to identify internal consistency in business skills. This analysis revealed a two-factor solution with 5 skills loading as a primary factor and 3 skills as a secondary factor, which are labeled Functional Skills and Interpersonal Skills. Finally, given the high reliability of all 8 items $($ alpha $=.82-.84)$ a combined rating was computed as an average.

Overall, students reported a significant increase in self-efficacy pre-to-post the case study and lab experiences. Prior to the case study and lab experience, students had an overall self-efficacy rating of 2.68, with functional skills at 2.29 and interpersonal skills at 3.34. Following the case study and lab experience, students overall self-efficacy rating significantly increased to 2.92 , with functional skills significantly increasing to 2.63 , showing a real gain in entrepreneurial skill confidence. Interestingly, interpersonal skills did not increase significantly, perhaps because they were the highest rated skills (both pre- and post-) and the case study and lab experiences did not require much teamwork or group interpersonal skill activity. 


\begin{tabular}{|c|c|c|c|c|}
\hline Functional Skill Factor* & $\underline{\text { Pre-Labs }}$ & Post-Labs & $\underline{\text { Diff }}$ & $\mathbf{p}<\#$ \\
\hline Recognize when an idea is good enough to support a major business venture & 2.52 & 2.73 & 0.21 & .114 \\
\hline Know the steps needed to finance a new business venture & 1.68 & 2.23 & 0.55 & .000 \\
\hline Pick the right marketing approach for the introduction of a new product or service & 2.38 & 2.76 & 0.38 & .006 \\
\hline Work with a supplier to get better prices & 2.53 & 2.76 & 0.23 & .108 \\
\hline Estimate accurately the costs of running a project & 2.33 & 2.70 & 0.36 & .004 \\
\hline Business Skills & $\overline{2.29}$ & $\overline{2.63}$ & $\overline{0.34}$ & $\overline{.000}$ \\
\hline \multicolumn{5}{|l|}{ Interpersonal Skill Factor* } \\
\hline Lead a team of people & 3.68 & 3.70 & 0.02 & .883 \\
\hline Communicate my ideas effectively to people in different positions or fields & 3.52 & 3.70 & 0.18 & .090 \\
\hline Promote my accomplishments to senior colleagues & 2.83 & 2.82 & -0.01 & .904 \\
\hline Interpersonal Skills & $\overline{3.34}$ & $\overline{3.40}$ & 0.06 & $\overline{.448}$ \\
\hline Entrepreneurial Self-Efficacy Rating & 2.68 & 2.92 & 0.24 & .002 \\
\hline
\end{tabular}

Table 6 - Student Self-Efficacy Ratings Pre- and Post-Case Study and Lab Experiences

The important entrepreneurial business skills of financing a new venture, marketing a new product and estimating costs showed significant ratings increases pre-to-post the case study and lab experience. This is encouraging because these skills were embedded into the case study experience and practicing them seemed to increase self-efficacy. On the downside, even with these gains, overall rating for Functional Skills was less than neutral (3.0) indicating that students did not see these skills as a competence.

We also explored how this change in entrepreneurial self-confidence impacted satisfaction with the case study experience and how this change related to career intent. We conducted a bivariate Pearson correlation (with two-tailed significance) on key variables relating to pre-to-post changes in self-efficacy, post lab self-efficacy ratings, case study/lab satisfaction (CSLS) scores and career intent ratings. The analysis revealed no correlation between pre-to-post change in selfefficacy score and CSLS $(\mathrm{r}=.054, \mathrm{p}=.664)$ or any measure of career intent. However, post lab self-efficacy score did significantly correlate with career intent for both "found a business" $(\mathrm{r}=.459, \mathrm{p}=.000)$ and "work for a global business" $(\mathrm{r}=.378, \mathrm{p}=.001)$, as shown in Table 6.

\begin{tabular}{|c|c|c|c|c|c|c|c|c|c|}
\hline \multicolumn{2}{|r|}{ Variable } & 1 & 2 & 3 & 4 & 5 & 6 & 7 & 8 \\
\hline 1 & Self-Efficacy (pre-post change) & -- & & & & & & & \\
\hline 2 & Self-Efficacy (post rating) & .415 & -- & & & & & & \\
\hline & CSLS Score (Satisfaction) & .054 & -.011 & -- & & & & & \\
\hline & Career Intent Ratings & & & & & & & & \\
\hline & Found a Business & .169 & .459 & -.075 & -- & & & & \\
\hline 5 & Work for a Start-Up Business & .074 & .179 & 149 & .691 & -- & & & \\
\hline 6 & Work for a Medium/Large Business & -.076 & .088 & .021 & -.131 & .095 & -- & & \\
\hline 7 & Work for a Global Business & .069 & .378 & .153 & -049 & -.123 & .519 & -- & \\
\hline & Work for the Government & -.063 & -.091 & .105 & -200 & -.168 & -.078 & -.074 & -- \\
\hline & Work for a Non-Profit & -.103 & -.064 & .056 & .056 & .164 & -.117 & -.184 & .352 \\
\hline
\end{tabular}

$\mathrm{n}=68$, all students who answered pre and post-self efficacy questions bold is significant

Table 6 - Correlation Coefficients for Case Study/Lab Satisfaction (CSLS) Scores, Self-Efficacy and Career Intent 
Based on this, we find support for our hypothesis that a case study experience can have a positive effect on a student's entrepreneurial self-efficacy. However, this change in self-efficacy did not translate into satisfaction with the case study experience. In a way, this is good news because it suggests that regardless of a student's satisfaction with the case method of instruction they can acquire important entrepreneurial business skills. This leads to our final question ...

\section{(Q4) Will students' career interest in entrepreneurship change pre-to-post a single entrepreneurial case study experience?}

Students' career intent was measured with a 6-item question that included a range of career choices. The sample for this analysis was all students who answered this question pre-lab and post-lab. To answer our research question we conducted a bivariate Pearson correlation (with two-tailed significance) on key variables relating to career intent comparing scores pre-lab experiences with scores post-lab experiences, as shown in Table 7.

\begin{tabular}{|c|c|c|c|c|}
\hline \multirow[b]{2}{*}{ Career Path } & \multicolumn{2}{|c|}{ Career Intent Ratings } & \multirow[b]{2}{*}{$\underline{\text { Diff }}$} & \multirow[b]{2}{*}{$\mathbf{p}<\#$} \\
\hline & Pre-Lab & Post-Lab & & \\
\hline Found a Business & 2.87 & 3.02 & $\overline{0.15}$ & .221 \\
\hline Work for a Start-Up Business & 3.66 & 3.45 & -0.21 & .040 \\
\hline Medium/Large US Business & 3.70 & 3.78 & 0.07 & .416 \\
\hline Global Business & 3.48 & 3.45 & -0.03 & .732 \\
\hline Government/Public Sector & 2.61 & 2.61 & 0.00 & 1.00 \\
\hline Non-Profit & 2.85 & 2.88 & 0.03 & .785 \\
\hline
\end{tabular}

Table 7 - Career Intent Ratings Pre- and Post-Lab Experiences

Not surprisingly, the pre-to-post change in entrepreneurial career intent ("founding a business") increased a non-significant $(+.15 \mathrm{p}=.221)$, given the relatively small sample size. The lack of any positive changes in career intent may simply reflect the difficulty in changing long-term career expectations through a short-term, single class experience. Interestingly, career intent actually decreased for "working for a start-up business" $(-.21, \mathrm{p}<.040)$, perhaps convincing some students not to just work for a start-up but actually start a company.

Based on this, we find no support for our hypothesis that students' career interest in entrepreneurship will change pre-to-post from a single entrepreneurial case study experience. However, these results might have been different if the intervention was a series of case study experiences, perhaps some focused on entrepreneurial careers and some focused on working at a larger, established business with all case study experiences focused on building an overall "business self-efficacy."

\section{Other Findings -}

Student Conceptual Map - As a course concluding exercise, students were asked to draw a map of the concepts included within this entire course experience. After brief instruction on conceptual maps, students were given a list of the topics covered in class (Appendix A) and asked to draw a map linking these ideas. We were interested in how students would link the 
entrepreneurial concepts in the context of the core engineering curriculum concepts. A summary version of the student conceptual map is shown in Figure 4.

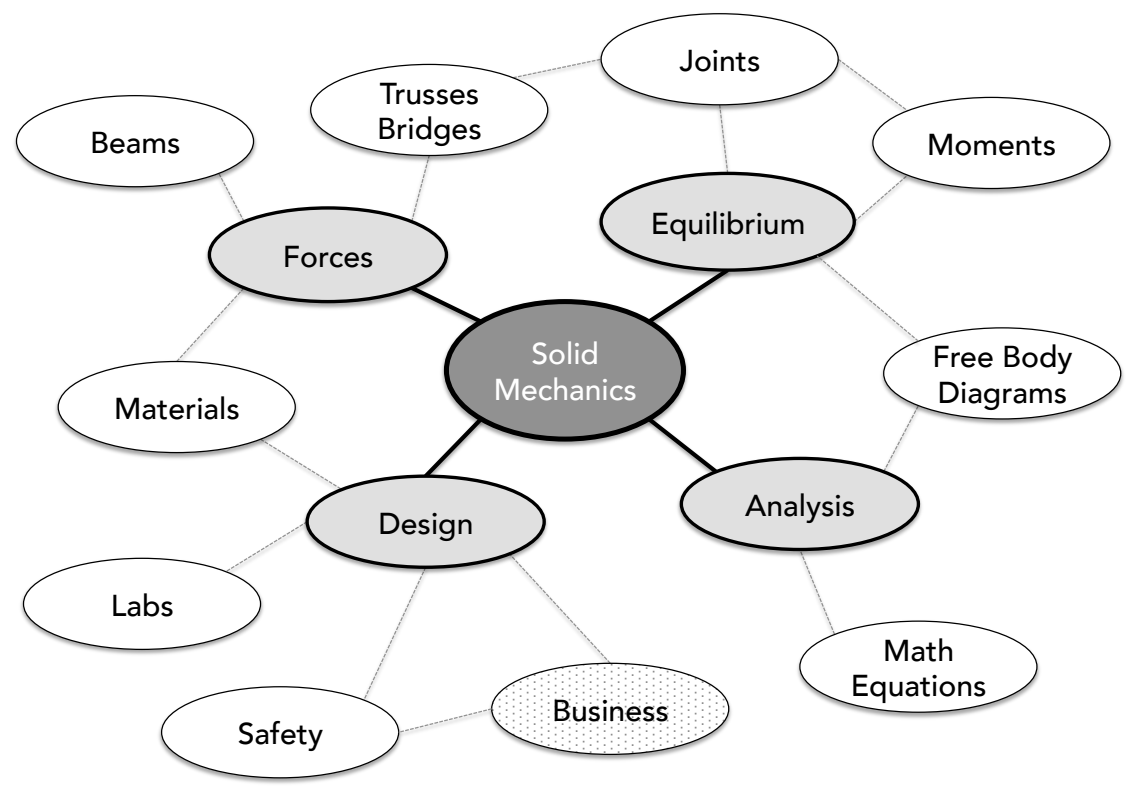

Figure 4 - Student Conceptual Map of Course Content

Most students placed the course name and meta-topic "Solid Mechanics" at the center of their map, which is not surprising given they tend to think of this class as a foundation for their own studies in mechanical engineering. The primary linking concepts to the core concept were "Analysis" and "Forces." "Analysis" seemed to include all the mathematics of the course and linked to Free Body Diagrams in practice. "Forces" was another primary linking concept, which was connected to "Beams" and "Trusses" (and a bridge building project), and to a lesser extent, "Materials."

There were two other primary linking concepts - "Equilibrium" and "Design." "Equilibrium" seemed to be the linking concept between "Forces" and "Analysis," using "Moments" and "Joints" as applications of equilibrium. "Design" was the fourth major linking concept and to a certain extent a catch-all for a variety of topics ranging from "Safety," "Labs," and "Business."

In the context of this research, we were pleased to see business concepts listed prominently in students' conceptual maps of course content. This gives encouragement for the idea that business concepts can be integrated into the flow of core engineering curriculum, in much the same way that the concepts of "Safety" and "Ethics" have been incorporated. This also reinforces the notion of "Design" as an inherent function of engineering, can influence a variety of core mechanical engineering concepts from "Materials" to "Analysis" techniques. 


\section{Discussion}

This was a pilot study, and as such, has many of the problems that are often encountered in exploratory, small-scale research. We know that the content learning measurement was limited and incomplete. The use of only 20 questions to cover learning over several subjects often resulted in one question linking to one topic, which is not an exhaustive way to measure learning. The questions themselves were not scaled prior to testing and the study design did not have an appropriate control, such as a randomized control trial. These deficiencies can be addressed in future versions of this research.

We were also troubled by the measured gain in pre-to-post learning, which on average was a net gain of about 3 correct questions out of 20 . We would expect with target content-specific instruction the measured gain in pre-to-post learning would be greater and approaching 100 percent correct. This indicates that we can do a better job of structuring the in-class lectures, discussion and worksheets to reinforce the targeted learning concepts. It also may mean that students learn in different ways and it may take more time to process this information.

We also struggle with the language of employment. For example, the differences between the terms "self-employed," "found a business" and "working for a start-up" may be difficult for a student to process, and may not even be relevant students. In this study, the career intent ratings between "self-employed" and "working for a start-up" were significant, and may be the result of a real difference in career intent or may be a function of loosely defined terms. The same issue relates to the term "entrepreneurship" which can mean anything from self-employment to working for a start-up. This is an area of interest for future research.

While the majority of students enjoyed the case study experience, particularly the hands-on lab exercises, there was a vocal minority that did not appreciate the insertion of business concepts into engineering curriculum. This is best illustrated by the following student feedback:

"Just stick to the engineering lab. It's cool that its about longboarding and all, but why have the crazy story about some startup with two people etc? Just do the lab and be done. All this random business stuff is annoying; you hear it all over campus already. This is an engineering class. Leave it that way. If I wanted business stuff and didn't care about engineering, I'd go be an [engineering business] major."

This issue can be addressed through better communication with the students about course objectives upfront. We believe that understanding core business concepts in the context of core engineering concepts will lead to better, more successful engineers long-term. Certainly ABET is moving in this direction. Perhaps it is important to discuss this issue early in the course experience and again before the case study/lab experiences to help students see the benefit.

A final issue of concern is faculty implementation. The development and delivery of this curriculum has proven to be challenging, as it requires an in-depth understanding of the core engineering concepts, an understanding of relevant entrepreneurial concepts, and the ability to tell an engaging story. The entrepreneurial business concepts introduced in the case study are 
often as new to the faculty as to the students. This leads to a relevant concern about their ability to teach the subject confidently. This can be addressed, at least partially, through the development of case study teaching notes, which can explain the concepts in greater detail and provide helpful tips on how to structure the case study/lab experience. We also need to gain experience with different college-level engineering student populations.

\section{Conclusion/Future Plans}

We are enthusiastic about the use of entrepreneurial case studies developed to teach core engineering curriculum. This can be an engaging tool for both the students and faculty, leading to better prepared engineering students who are ready to succeed in the workplace.

In the near future, we can see 2-3 case study stories specifically developed for an introductory solid mechanics course that incorporate the language and concepts of basic business skills. We also have an interest in expanded testing of this curriculum at both larger institutions and geographically diverse locations.

Long-term, these case studies and associated activities could become part of a library of similar curriculum for other core engineering disciplines, available for sharing and improvement. This requires resources and we plan on seeking outside funding for the next phase of development.

The authors would like to acknowledge the special effort of the Course Assistants - Jun Kyu Lee, Jason Walker, Kathy Tong, Colette Posse, Juliana Velez and Matthew Bandelt - who read (and re-read) the case study materials, tested the labs, completed the worksheets and helped make the execution of this curriculum possible in the classroom. We also owe a debt of gratitude to members of the Designing Education Lab at Stanford University - Annette Boehmer, Helen Chen, Shannon Gilmartin, Janna Rodrigues and Michelle Warner - who provided proofreading, commentary, references, advice and general comfort throughout this life of this project.

The case study materials, including the case study story, lab instructions, materials list and worksheets are available for download at the Designing Education Lab (del.stanford.edu) website: Madison Longboard 


\section{Appendix A \\ Solid Mechanics Course Concepts}

Math Basics

Dot product

Cross-product vector notation

Vector addition

Right-handed coordinate system

Weight (lbs or newtons)

Conversion between $\mathrm{lbs}$ and $\mathrm{N}$

Mass $(\mathrm{kg})$ and force $(\mathrm{N})$ on earth

Basic trigonometry relationships

Significant figures

\section{Forces}

External forces

Internal forces

Magnitude of a force

Force defined in terms of space angles

Newton's second law

Newton's third law

Fluid pressure force

Drag force

Normal or contact force

Shear force

Friction force

\section{Moments}

Moment Center

Equivalent Load

Couple

Position vector

A $\times \mathrm{F}=\mathrm{M}$

Double-headed arrow

Torque vs. Moment

\section{Equilibrium}

$\operatorname{sum}(\mathrm{M})=0$

$\operatorname{sum}(F)=0$

$\mathrm{Fx}^{*} \mathrm{i}+\mathrm{Fy}^{*} \mathrm{j}+\mathrm{Fz}^{*} \mathrm{k}=0>$

$\mathrm{Fx} * \mathrm{i}+\mathrm{Fy} * \mathrm{j}=0>$

$\mathrm{Mx} * \mathrm{i}+\mathrm{My} * \mathrm{j}+\mathrm{Mz}^{*} \mathrm{k}=0>$

$\mathrm{Mz}^{*} \mathrm{k}=0$

Two force member

Three force member

Zero force member

\section{Friction}

Static coefficient of friction

Kinetic coefficient of friction

Normal force and friction force

Smooth surface

\section{Materials}

Young's Modulus

Modulus of Elasticity (E)

Ultimate or tensile strength

Brittle failure

Ductile failure

Compressive failure

Properties of Steel

Aluminum alloy

Stress

Strain

Normal stress

Shear stress

$\mathrm{MPa}$

$\mathrm{m} / \mathrm{m}$

psi

Beams

Shear force $(\mathrm{V})$

Bending moment $(\mathrm{Mb})$

Cantilever beam

Simply supported beam

Neutral axis

Bending moment diagram

Neutral axis

Shear force diagram

$\mathrm{dM} / \mathrm{dx}=\mathrm{V}$

Deflection

Trusses

Statically indeterminate

Statically determinan

Stable/Unstable

Method of joints

Method of sections

Compressive failure

Buckling failure

Area moment of inertia (I)

Free-Body Diagrams

Bearings

Pin joints

Planar system

Non-planar system

Fixed boundary condition

Smooth surface

Sufficient friction

Well-aligned bearings

Thrust bearing

Cable tension

Isometric view

Planar view

Ball-and-socket

Boundary
Engineering Professionalism

Professional Engineer

Engineering ethics

Safety factor

Dynamic load factor

Documentation of work

Important questions

Checking answers

Assumptions

Manufacturing considerations

Technical report

Elevator pitch

Poster presentation

Prototyping

Team work dynamics

Design

Tower design

Skateboard truck design

Skateboard deck design

Bridge design

Bicycle design

Design for safety

Design brainstorming

Analysis of Machines

Multiple FBD's

Exposed internal force pairs

Simplified analysis procedures

Mechanical advantage

Entrepreneurial Concepts

Business model

Value proposition

Revenue model

Cost model

Profit model

Vision statement

Mission statement

SWOT analysis

Business risk

Business uncertainty 


\section{References}

1. National Survey of Recent College Graduates. US National Science Foundation (NSF); 2008 Oct p. Table 4142. Report No.: NSF 12-328.

2. The Engineer of 2020: Visions of Engineering in the New Century. National Academy of Engineering; 2004 p. 118.

3. Jamieson LH, Lohmann JR. Innovation with Impact: Creating a Culture for Scholarly and Systematic Innovation in Engineering Education. Washington DC: American Society for Engineering Education; 2012 Jun p. 77.

4. Duval-Couetil N, Reed-Rhoads T, Haghighi S. Engineering Students and Entrepreneurship Education: Involvement, Attitudes and Outcomes. International Journal of Engineering Education. 2012;28(2):425.

5. Neck HM, Greene PG. Entrepreneurship education: Known worlds and new frontiers. Journal of Small Business Management. 2011;49(1):55-70.

6. Rippin A, Booth C, Bowie S, Jordan J. A Complex Case: Using the case study method to explore uncertainty and ambiguity in undergraduate business education. Teaching in Higher Education. 2002;7(4):429-41.

7. Banning KC. The effect of the case method on tolerance for ambiguity. Journal of Management Education. 2003;27(5):556-67.

8. Practice $\mathrm{C}$ on $\mathrm{D}$ in the $\mathrm{S}$ of $\mathrm{L}$ with additional material from the $\mathrm{C}$ on $\mathrm{LR}$ and $\mathrm{E}$, Council NR. How People Learn: Brain, Mind, Experience, and School: Expanded Edition. 2nd ed. National Academies Press; 2000.

9. Harris CE, Davis M, Pritchard MS, Rabins MJ. Engineering ethics: what? why? how? and when? Journal of Engineering Education. 1996;85:93-6.

10. Weaver J, Rayess N. Developing Entrepreneurially Minded Engineers by Incorporating Technical Entrepreneurship Case Studies. The Journal of Engineering Entrepreneurship. 2010;2(1):10-27.

11. Garcia J, Sinfield J, Yadav A, Adams R. Learning Through Entrepreneurially Oriented Case-Based Instruction. International Journal of Engineering Education. 2012;28(2):448.

12. Brown T. Design Thinking. Harvard Business Review. 2008 Jun;11.

13. Stanford Institute of Design | d.school | home [Internet]. [cited 2009 May 23]. Available from: http://www.stanford.edu/group/dschool/

14. Steinbeck R. Building Creative Competence in Globally Distributed Courses through Design Thinking. Scientific Journal of Media Literacy. 2011;27.

15. Lent RW, Brown SD, Hackett G. Toward a unifying social cognitive theory of career and academic interest, choice, and performance. Journal of Vocational Behavior. 1994;

16. Lent RW, Brown SD. On conceptualizing and assessing social cognitive constructs in career research: A measurement guide. Journal of Career Assessment. 2006;14(1):12-35.

17. Lent RW, Singley D, Sheu H-B, Schmidt JA, Schmidt LC. Relation of Social-Cognitive Factors to Academic Satisfaction in Engineering Students. Journal of Career Assessment. 2007 Feb 1;15(1):87-97.

18. Bandura A. Social cognitive theory: An agentic perspective. Annual review of psychology. 2001;52(1):1-26. 
19. Bandura A. Social Cognitive Theory of Mass Communication. Media Psychology. 2001;3(3):265-99.

20. Sheppard SD, Tongue BH. Statics: Analysis and Design of Systems in Equilibrium. Second Edition. Wiley; 2006.

21. Byers TH, Dorf RC, Nelson AJ. Technology ventures: from idea to enterprise. McGraw-Hill; 2011.

22. Stanford University Alumni Survey [Internet]. 2009. Available from: http://www.stanford.edu/dept/presprovost/irds/ir/survey_research/Alum2009.pdf

23. Matusovich HM, Sheppard S, Atman C, Streveler RA, Miller RL. Work in progress - Engineering pathways study: The college-career transition. Frontiers in Education Conference (FIE), 2011. 2011. p. S1F-1 -S1F-3.

24. Simard C, Henderson AD, Gilmartin SK, Schiebinger L, Whitney T. Climbing the technical ladder: Obstacles and solutions for mid-level women in technology. Anita Borg Institute and Stanford University. 2008;

25. Turns J, Atman CJ, Adams R. Concept maps for engineering education: A cognitively motivated tool supporting varied assessment functions. Education, IEEE Transactions on. 2000;43(2):164-73.

26. Besterfield-Sacre M, Gerchak J, Lyons MR, Shuman LJ, Wolfe H. Scoring concept maps: An integrated rubric for assessing engineering education. Journal of Engineering Education. 2004;93(2):105-16.

27. Antoncic B, Hisrich RD. Clarifying the intrapreneurship concept. Journal of small business and enterprise development. 2003;10(1):7-24. 